\title{
Article
}

\section{Very Long-Term Follow-Up in Cardiac Resynchronization Therapy: Wider Paced QRS Equals Worse Prognosis}

\author{
Patrick Leitz ${ }^{*}+$, Julia Köbe ${ }^{+} \mathbb{D}$, Benjamin Rath, Florian Reinke, Gerrit Frommeyer (D), Christian Andresen, \\ Fatih Güner, Julian Wolfes, Philipp S. Lange, Christian Ellermann ${ }^{\mathbb{D}}$, Lars Eckardt ${ }^{\dagger}$ and Dirk G. Dechering ${ }^{\dagger}$
}

check for updates

Citation: Leitz, P.; Köbe, J.; Rath, B.; Reinke, F.; Frommeyer, G.; Andresen, C.; Güner, F.; Wolfes, J.; Lange, P.S.; Ellermann, C.; et al. Very Long-Term Follow-Up in Cardiac Resynchronization Therapy: Wider Paced QRS Equals Worse Prognosis. J Pers. Med. 2021, 11, 1176. https:// doi.org/10.3390/jpm11111176

Academic Editor: Yuji Nagatomo

Received: 29 September 2021

Accepted: 9 November 2021

Published: 11 November 2021

Publisher's Note: MDPI stays neutral with regard to jurisdictional claims in published maps and institutional affiliations.

Copyright: (c) 2021 by the authors. Licensee MDPI, Basel, Switzerland. This article is an open access article distributed under the terms and conditions of the Creative Commons Attribution (CC BY) license (https:/ / creativecommons.org/licenses/by/ $4.0 /)$.
Department of Cardiology II-Electrophysiology, Albert-Schweitzer-Campus 1, University Hospital Muenster, 48149 Muenster, Germany; julia.koebe@ukmuenster.de (J.K.); benjamin.rath@ukmuenster.de (B.R.); florian.reinke@ukmuenster.de (F.R.); gerrit.frommeyer@ukmuenster.de (G.F.); christian.andresen@ukmuenster.de (C.A.); fatih.guener@ukmuenster.de (F.G.); julian.wolfes@ukmuenster.de (J.W.); philippsebastian.lange@ukmuenster.de (P.S.L.); christian.ellermann@ukmuenster.de (C.E.); lars.eckardt@ukmuenster.de (L.E.); dirk.dechering@niels-stensen-kliniken.de (D.G.D.)

* Correspondence: Patrick.Leitz@ukmuenster.de

† Authors contributed equally.

Abstract: Background: Different electrocardiogram (ECG) findings are known to be independent predictors of clinical response to cardiac resynchronization therapy (CRT). It remains unknown how these findings influence very long-term prognosis. Methods and Results: A total of 102 consecutive patients (75 males, mean age $65 \pm 10$ years) referred to our center for CRT implantation had previously been included in this prospective observational study. The same patient group was now re-evaluated for death from all causes over a prolonged median follow-up of 10.3 years (interquartile range 9.4-12.5 years). During follow-up, 55 patients died, and $82 \%$ of the clinical non-responders $(n=23)$ and $44 \%$ of the responders $(n=79)$ were deceased. We screened for univariate associations and found QRS width during biventricular (BIV) pacing $(p=0.02)$, left ventricular $(\mathrm{LV})$ pacing $(p<0.01), \Delta \mathrm{LV}$ paced-right ventricular $(\mathrm{RV})$ paced $(p=0.03)$, age $(p=0.03)$, New York Heart Association (NYHA) class $(p<0.01), \mathrm{CHA}_{2} \mathrm{DS}_{2}$-Vasc score $(p<0.01)$, glomerular filtration rate $(p<0.01)$, coronary artery disease $(p<0.01)$, non-ischemic cardiomyopathy (NICM) $(p=0.01)$, arterial hypertension $(p<0.01)$, NT-proBNP $(p<0.01)$, and clinical response to CRT $(p<0.01)$ to be significantly associated with mortality. In the multivariate analysis, NICM, the lower NYHA class, and smaller QRS width during BIV pacing were independent predictors of better outcomes. Conclusion: Our data show that QRS width duration during biventricular pacing, an ECG parameter easily obtainable during LV lead placement, is an independent predictor of mortality in a long-term follow-up. Our data add further evidence that NICM and lower NYHA class are independent predictors for better outcome after CRT implantation.

Keywords: cardiac resynchronization; heart failure; very long-term follow-up; ECG; pacing

\section{Introduction}

Heart failure (HF) remains a leading cause of mortality in the western world [1]. Advances in pharmacological and device therapy have played a key role in improving survival and quality of life in patients with HF and reduced ejection fraction (HFrEF). Cardiac resynchronization therapy (CRT), which was first introduced over 30 years ago, has advanced to be a cornerstone of HFrEF therapy. A multitude of studies were able to demonstrate a positive effect of CRT therapy on mortality, quality of life, and left ventricular ejection fraction (LVEF) in patients with left bundle branch block (LBBB) [2,3]. However, there remains a significant portion of patients with a class I indication for CRT implantation, according to current guidelines, who do not benefit from CRT.

In a previous study [4] we were able to show electrocardiographic measurements such as shorter QRS duration during left ventricular (LV) pacing, and especially a shorter 
LV paced than right ventricular (RV) paced QRS width, to be independent predictors for short-term CRT response. Several consecutive studies have demonstrated a beneficial short-term effect of acute QRS narrowing in the presence of LBBB [5]. As long-term data on the effect of QRS changes during CRT pacing are sparse, we re-evaluated different electrocardiographic and clinical variables as predictors for very long-term survival in our previously described cohort [4] of HFrEF patients with an indication for CRT, according to the European Society of Cardiology (ESC) guidelines from that time.

\section{Patients and Methods}

\subsection{Study Design and Data Collection}

The present study is in accordance with regional and institutional ethics guidelines. The local ethics committee (Ethik-Kommission der Ärztekammer Westfalen-Lippe und der Westfälischen Wilhelms-Universität) approved the data collection. The primary endpoint was defined as death from any cause. Secondary endpoints were hospitalization due to heart failure.

Initially, all patients presented with persistent symptomatic heart failure (New York Heart Association (NYHA) class II-IV) despite optimal medical therapy and had a native QRS complex width $>120 \mathrm{~ms}$. Decision for CRT implantation was made according to the then applicable ESC guidelines [6]. The LV lead position was in all cases lateral or posterolateral. The follow-up design is represented in Figure 1.

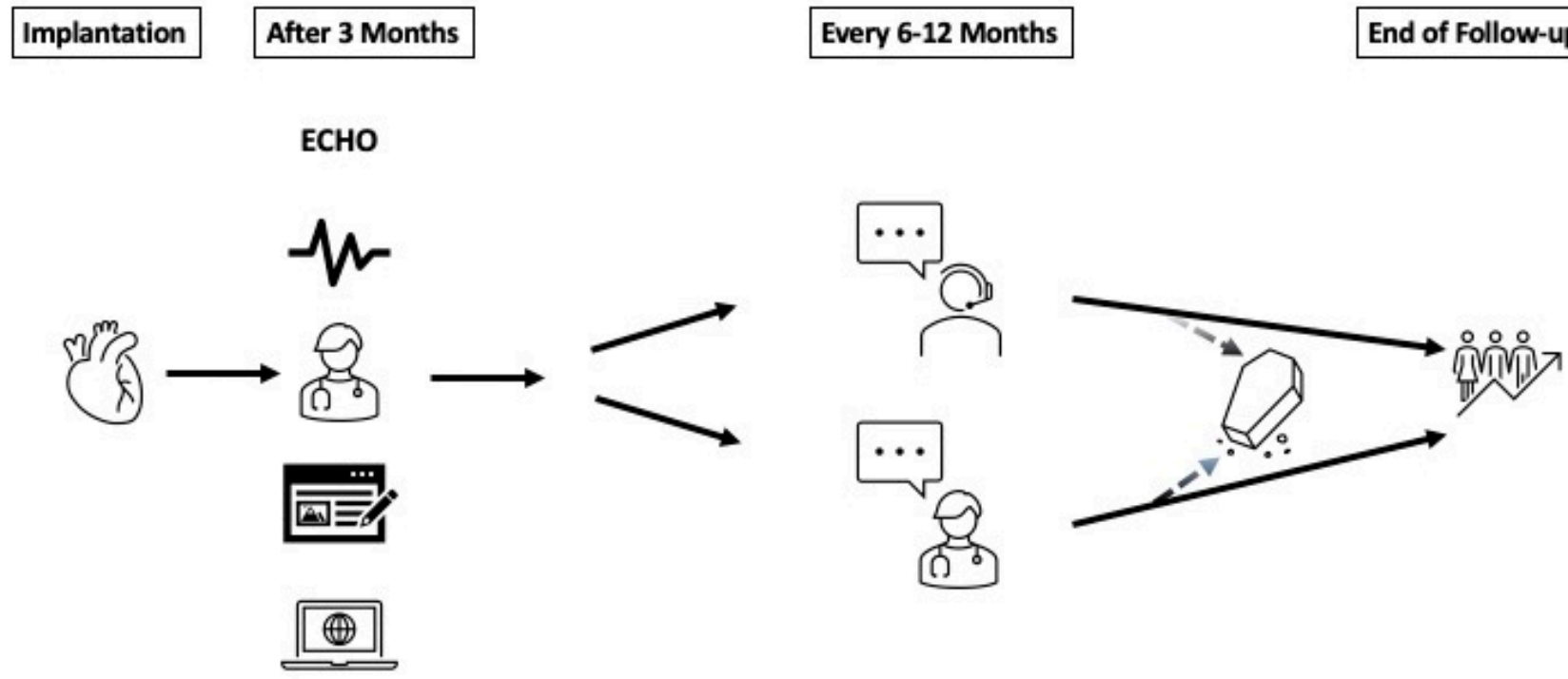

\footnotetext{
Figure 1. Follow-up design (

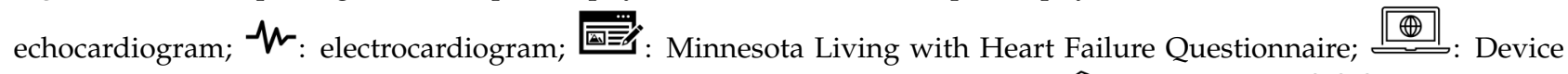
interrogation; $\cdots$ : Interrogation on current NYHA class, hospitalizations; collection and start statistical analysis).
}

\subsection{Initial ECG Recordings}

Standard supine 12-lead electrocardiogram (ECG) $(50 \mathrm{~mm} / \mathrm{s}, 10 \mathrm{~mm} / \mathrm{mV})$ results were obtained at baseline, perioperatively, and after 3 months. Intrinsic rhythm, LV paced, $\mathrm{RV}$ paced, and biventricular (BIV) paced ECG at a heart rate of $70 \mathrm{bpm}$, respectively, were documented. These recordings were then analyzed with regard to QRS duration using Datinf Measure software (Datinf GmbH, Tübingen, Germany). Regarding QRS width, only the widest QRS complex of the 12-lead ECG was used for analysis. 


\subsection{Definition of CRT Responders}

Response to CRT was defined as improvement in NYHA class $>1$ based upon the Minnesota Living with Heart Failure Questionnaire. Non-responders were defined as lack of improvement or even worsening of NYHA class and/or at least one heart failure hospitalization with intravenous diuretic use. In order to reassess adequate resynchronization, all patients classified as non-responders were re-evaluated by echocardiography at 3- or 6-months follow-up. Optimization of device programming was done according to a stepwise approach [7].

\subsection{Definition of Ischemic Cardiomyopathy vs. Non-Ischemic Cardiomyopathy}

Ischemic cardiomyopathy (ICM) was defined as a reduction in LVEF due to a history of MI or revascularization (coronary artery bypass grafting (CABG) or percutaneous coronary intervention (PCI)), or patients with $\geq 75 \%$ stenosis of the left main or proximal left anterior descending coronary artery (LAD), or patients with $\geq 75 \%$ stenosis of two or more epicardial vessels. Patients with single-vessel disease and no prior history of revascularization or myocardial infarction (MI) were classified as non-ischemic (NICM).

\subsection{Long-Term Follow-Up Collection}

Long-term follow-up data were gathered from our outpatient clinic, where patients were seen every 6-12 months. Patients who were not regularly seen in our clinic were contacted by phone. In these cases, their treating physician was also contacted. During the visits/telephone interviews, patients' data on the current NYHA class and hospitalizations, including the reason for hospitalization, were retrieved. If a patient missed a follow-up visit and could not be reached by phone, the general physician was contacted. All patients deaths were confirmed by the treating general physician. Data were collected from the electronic hospital information system.

\subsection{Statistical Analysis}

Statistical analysis was performed using SPSS (Version 25, IBM SPSS Statistics, IBM Corporation, Armonk, NY, USA). Continuous data were expressed as mean \pm SD and compared between groups using a Mann-Whitney U Test. Categorical data were summarized by their observed frequencies and percentages, and compared using cross tabulation and a Chi-square Test.

Univariable and multivariable Cox regression analyses were performed to determine the parameters associated with very long-term survival. Associations with survival were further described with hazard ratios and $95 \%$ confidence intervals. The multivariable Cox regression model included variables with univariate $p<0.05$. Additionally, clinical characteristics with known association with survival in the described cohort were forced into different multivariable models, regardless of the univariate $p$ value. To avoid intercorrelations, only one of the ECG parameters was forced into each model. Only parameters that showed a significant association throughout all of the constructed models were labelled as significant predictors. Finally, survival rates were depicted with Kaplan-Meier curves with their corresponding tables showing the number of patients at risk at different corresponding points of follow-up. For all statistical tests a value of $p<0.05$ was considered significant.

\section{Results}

\subsection{Baseline Characteristics}

The basis for the presented analysis is the previously described cohort [4]: A total of 102 consecutive patients referred to our center for CRT implantation were initially enrolled, and 14 patients were lost to follow-up at some point. Two patients presented with a right bundle branch block (RBBB) masking LBBB. Native QRS duration at implantation was $166 \pm 33 \mathrm{~ms}$. The mean age of the cohort was $70 \pm 10$ years old at the time of implantation; 
$66 \%$ of the patients were male. Further baseline characteristics of our population, as well as the ECG measurements, are listed in Table 1.

Table 1. Patient characteristics at the time of implantation and ECG parameters (NYHA: New York Heart Association; GFR: glomerular filtration rate; NICM: non-ischemic cardiomyopathy; ng/L: nanogram per liter; LVEF: left ventricular ejection fraction; BIV: bBiventricular; LV: left ventricular; $\mathrm{RV}$ : right ventricular; $\Delta$ : difference; ms: milliseconds; $\mathrm{kg}$ : kilogram).

\begin{tabular}{|c|c|c|c|c|}
\hline & $\begin{array}{c}\text { Survivors } \\
n=36\end{array}$ & $\begin{array}{c}\text { Deceased } \\
n=52\end{array}$ & $\begin{array}{c}\text { Entire } \\
\text { Population } \\
n=102\end{array}$ & $p$-Value \\
\hline Age (Years) & $70 \pm 10$ & $76 \pm 9$ & $74 \pm 10$ & 0.03 \\
\hline Weight (kg) & $86 \pm 16$ & $86 \pm 19$ & $85 \pm 19$ & 0.56 \\
\hline NYHA Class & $2.7 \pm 1$ & $3.17 \pm 1$ & $3.4 \pm 1.2$ & $<0.001$ \\
\hline $\mathrm{CHA}_{2} \mathrm{DS}_{2}$-Vasc & $3.4 \pm 2.7$ & $5.5 \pm 2.5$ & $4.7 \pm 2.7$ & $<0.001$ \\
\hline GFR $(\mathrm{mL} / \mathrm{min})$ & $56.7 \pm 6.7$ & $48.3 \pm 12.8$ & $51.4 \pm 11.6$ & 0.007 \\
\hline Atrial Fibrillation (\%) & 47.4 & 49.1 & 47 & 0.94 \\
\hline Arterial Hypertension (\%) & 50 & 61.8 & 62 & 0.116 \\
\hline Type II Diabetes (\%) & 26.3 & 29.1 & 28 & 0.818 \\
\hline Coronary artery disease (\%) & 23.7 & 60 & 45 & 0.01 \\
\hline NICM (\%) & 86.5 & 51.9 & 67.3 & 0.01 \\
\hline Male Gender (\%) & 65.8 & 85.5 & 75 & 0.042 \\
\hline Clinical Responder (\%) & 89.5 & 67.3 & 77.5 & 0.014 \\
\hline LVEF (\%) & $30.7 \pm 12.3$ & $28.8 \pm 7.7$ & $29.4 \pm 9.7$ & 0.77 \\
\hline NT-proBNP (ng/L) & $1534 \pm 1781$ & $5339 \pm 7676$ & $3658 \pm 6086$ & 0.02 \\
\hline No pacing (ms) & $162.6 \pm 33$ & $170.3 \pm 34.8$ & $166.6 \pm 33.3$ & 0.173 \\
\hline BIV pacing (ms) & $149.3 \pm 27.8$ & $173.7 \pm 30.2$ & $162.0 \pm 31.4$ & $<0.001$ \\
\hline LV pacing (ms) & $177.5 \pm 33.8$ & $202 \pm 40.4$ & $191.5 \pm 38.4$ & $<0.001$ \\
\hline $\mathrm{RV}$ pacing (ms) & $199.9 \pm 28.3$ & $210.7 \pm 34.7$ & $205.7 \pm 32.4$ & 0.035 \\
\hline$\Delta \mathrm{LV}$ paced-RV paced $(\mathrm{ms})$ & $-22.4 \pm 37.2$ & $-8.7 \pm 30.8$ & $-14.5 \pm 33.6$ & 0.078 \\
\hline
\end{tabular}

\subsection{Follow-Up Duration}

The first CRT implantation enrolled in the study took place on 1 January 2004, and follow-up ended for all patients on 22 September 2019. The shortest censored time was 8 years, 6 months, and 7 days. The longest censored time was 15 years, 2 months, and 26 days. Median follow-up was 10.3 years (interquartile range 9.4-12.5 years).

\subsection{Adverse Events}

During a total of 924 years of patient follow-up, three patients developed devicerelated infections with the need of antibiotic therapy. Two patients suffered a stroke, one patient underwent transcatheter aortic valve replacement, and one patient had a ST elevation myocardial infarction (STEMI). Due to terminal heart failure, three patients underwent left ventricular assist device implantation to bridge for heart transplantation. All three patients received a heart transplant further down the line.

\subsection{Survival}

Survival censored at $36,60,96$, and 120 months was $89 \%, 83 \%, 62 \%$, and $51 \%$, respectively. Median survival was 126 months. 


\subsection{Possible Predictors of Long-Term Outcomes}

Results from the univariate and multivariate Cox regression for the primary and secondary endpoints are found in Table 2.

Table 2. Uni- and multivariate Cox regression for the primary and secondary endpoints of patient characteristics at the time of implantation and ECG parameters (BIV: bBiventricular; LV: left ventricular; RV: right ventricular; $\triangle$ : difference; NYHA: New York Heart Association; GFR: glomerular filtration rate; NICM: non-ischemic cardiomyopathy; ng/L: nanogram per liter; LVEF: left ventricular ejection fraction; HR: hazard ratio; 95\% CI: 95\% confidence interval).

\begin{tabular}{|c|c|c|c|c|}
\hline & Primary Endpoint & Primary Endpoint & Secondary Endpoint & Secondary Endpoint \\
\hline & $\begin{array}{c}p \text {-Value } \\
\text { Univariate Cox } \\
\text { Regression } \\
\{\text { HR }(95 \% \text { CI })\}\end{array}$ & $\begin{array}{c}p \text {-Value } \\
\text { Multivariate Cox } \\
\text { Regression }\{\mathrm{HR} \\
(95 \% \mathrm{CI})\}\end{array}$ & $\begin{array}{c}p \text {-Value } \\
\text { Univariate Cox } \\
\text { Regression } \\
\{\text { HR }(95 \% \text { CI })\}\end{array}$ & $\begin{array}{c}p \text {-Value } \\
\text { Multivariate Cox } \\
\text { Regression } \\
\{\text { HR }(95 \% \text { CI })\}\end{array}$ \\
\hline $\begin{array}{l}\text { QRS width with } \\
\text { no pacing }\end{array}$ & $0.09\{1.01(0.99-1.02)\}$ & & $0.3\{1.00(1.00-1.01)\}$ & \\
\hline $\begin{array}{c}\text { QRS width } \\
\text { during BIV pacing }\end{array}$ & $0.02\{2.51(1.39-4.57)\}$ & $0.01\{3.89(1.36-11.14)\}$ & $0.05\{1.57(1.00-2.49)\}$ & \\
\hline $\begin{array}{l}\text { QRS width during } \\
\text { LV pacing }\end{array}$ & $<0.001\{1.01(1.01-1.02)\}$ & & $0.006\{1.01(1.00-1.02)\}$ & \\
\hline $\begin{array}{l}\text { QRS width during } \\
\text { RV pacing }\end{array}$ & $0.09\{1.01(1.00-1.02)\}$ & & $0.12\{1.01(0.99-1.01)\}$ & \\
\hline $\begin{array}{c}\Delta Q R S \text { width during } L V \\
\text { paced- QRS width } \\
\text { during RV paced }\end{array}$ & $0.03\{1.01(1.00-1.02)\}$ & & $0.19\{1.00(0.99-1.01)\}$ & \\
\hline Age (Years) & $0.03\{1.04(1.00-1.07\}$ & & $0.07\{1.02(0.99-1.04)\}$ & \\
\hline Male Gender (\%) & $0.074\{0.48(0.21-1.07)\}$ & & $0.1\{0.63(0.36-1.09)\}$ & \\
\hline Weight $(\mathrm{kg})$ & $0.52\{0.99(0.98-1.01)\}$ & & $0.56\{1.00(0.99-1.02)\}$ & \\
\hline NYHA Class & $<0.001\{2.40(1.40-4.13)\}$ & $0.03\{2.46(1.08-5.58)\}$ & $0.01\{1.68(1.31-2.48)\}$ & $0.04\{1.71(1.02-2.88)\}$ \\
\hline $\mathrm{CHA}_{2} \mathrm{DS}_{2}$-Vasc & $<0.001\{1.24(1.10-1.40)\}$ & & $0.07\{1.13(1.03-1.23)\}$ & \\
\hline GFR (ml/min) & $0.007\{0.96(0.93-0.98)\}$ & & $0.19\{0.98(0.96-1.01)\}$ & \\
\hline Atrial Fibrillation (\%) & $0.94\{0.75(-0.53-0.69)\}$ & & $0.97\{1.01(0.64-1.59)\}$ & \\
\hline $\begin{array}{c}\text { Arterial Hypertension } \\
(\%)\end{array}$ & $0.004\{1.62(1.17-2.25)\}$ & & $0.11\{1.31(0.94-1.81)\}$ & \\
\hline Type II Diabetes (\%) & $0.818\{0.94(-0.70-0.63)\}$ & & $0.922\{1.03(0.62-1.70)\}$ & \\
\hline $\begin{array}{l}\text { Coronary artery } \\
\text { disease }(\%)\end{array}$ & $0.001\{2.81(1.56-5.05)\}$ & & $0.002\{2.04(1.29-3.23)\}$ & \\
\hline NICM (\%) & $0.01\{0.31(0.17-0.56)\}$ & $0.003\{0.23(0.09-0.60)\}$ & $0.004\{0.49(0.30-0.80)\}$ & \\
\hline Clinical Responder (\%) & $0.008\{0.44(0.24-0.81)\}$ & $0.77\{0.85(0.27-2.63)\}$ & $0.03\{0.56(0.32-0.95)\}$ & \\
\hline $\operatorname{LVEF}(\%)$ & $0.56\{0.99(0.95-1.03)\}$ & & $0.30\{0.99(0.96-1.01)\}$ & \\
\hline NT-proBNP (ng/L) & $<0.001\{1.0(1.0-1.0)\}$ & & $<0.001\{1.0(1.0-1.0)\}$ & \\
\hline
\end{tabular}

Regarding our primary endpoint, using a univariate analysis of age $(p=0.03)$, NYHA class $(p<0.001), \mathrm{CHA}_{2} \mathrm{DS}_{2}$-Vasc score $(p<0.001)$, glomerular filtration rate (GFR) $(p=0.007)$, arterial hypertension $(p=0.004)$, presence of coronary artery disease $(p=0.001)$, presence of non-ischemic (versus ischemic) cardiomyopathy (NICM; $p=0.01$ ), clinical response to resynchronization therapy $(p=0.008)$, and NT-proBNP $(p<0.001)$, the results showed a significant association with survival.

Of the electrocardiographic parameters, native QRS width and RV paced values failed to reach statistical significance in the univariate analysis. 
Multivariate analysis retained NYHA class $(p=0.03)$, presence of NICM $(p=0.003)$, and QRS width during BIV stimulation $(p=0.01)$ as independent predictors of survival.

We further performed stratified analysis to evaluate the robustness of our data. QRS width during BIV stimulation in the subgroups of men $(p=0.04)$, patients with wider native QRS ( $p=0.006)$ throughout all age groups ( $p=0.04$ in the younger $(<74$ years) and $p=0.05$ for the elder half group) remained statistically significant. NYHA class showed significant associations only in men $(p=0.01)$ and the younger half group $(p<0.04)$. Finally, NICM remained statistically significant only in the elderly $(p=0.02)$. Kaplan-Meier curves for survival are shown in Figure 2. Concerning the secondary endpoint in the multivariate Cox regression analysis, only the NYHA class at the time of implantation revealed to be an independent predictor of hospitalization. None of our ECG parameters reached statistical significance in the multivariate Cox model.

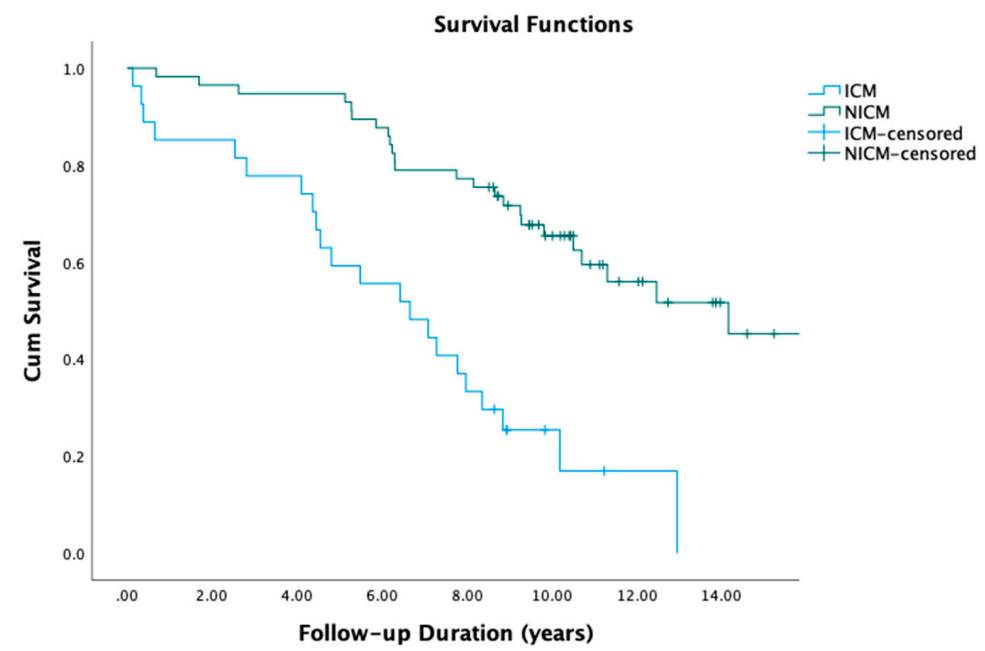

\begin{tabular}{ccccccccc}
\hline No. at risk & 0 years FU & 2 years FU & 4 years FU & 6 years FU & 8 years FU & 10 years FU $\mathbf{1 2}$ years FU $\mathbf{1 4}$ years FU \\
\hline ICM & 28 & 23 & 21 & 15 & 9 & 7 & 6 & 5 \\
\hline DCM & 60 & 55 & 54 & 50 & 44 & 37 & 34 & 44 \\
\hline
\end{tabular}

(A)

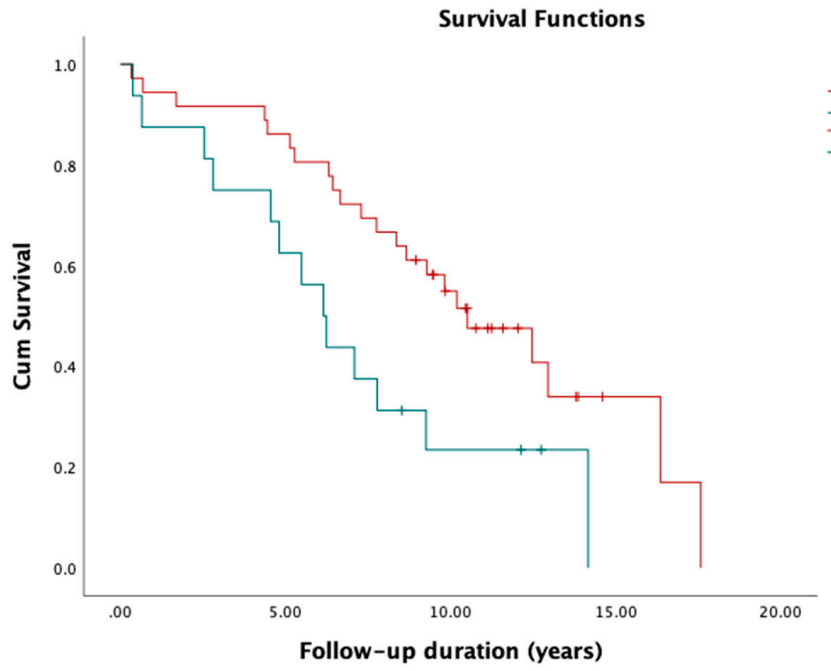

\begin{tabular}{ccccccccc}
\hline No. at risk & $\mathbf{0}$ years FU & 2 years FU & 4 years FU & $\mathbf{6}$ years FU & $\mathbf{8}$ years FU & $\mathbf{1 0}$ years FU & $\mathbf{1 2}$ years FU & $\mathbf{1 4}$ years FU \\
\hline NYHA III & 36 & 33 & 33 & 29 & 24 & 20 & 18 & 16 \\
\hline NYHA IV & 16 & 14 & 12 & 9 & 5 & 4 & 4 & 4 \\
\hline
\end{tabular}

Figure 2. Cont. 


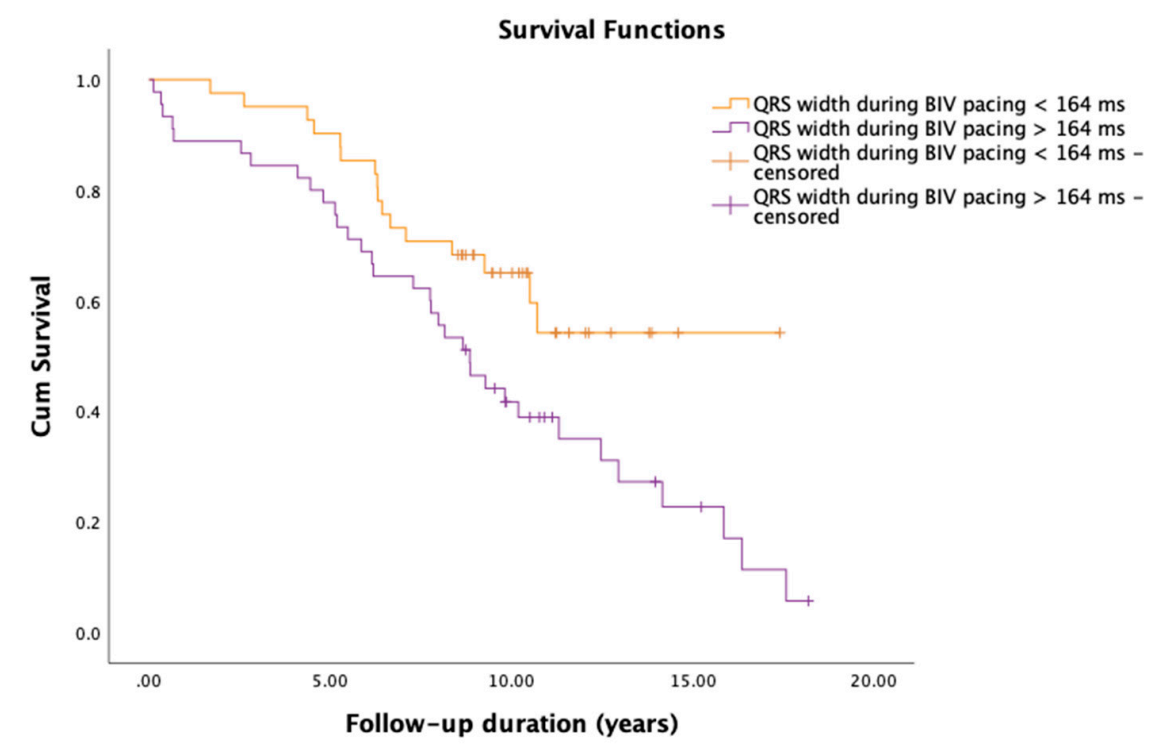

\begin{tabular}{ccccccccc}
\hline No. at risk & 0 years FU & 2 years FU & 4 years FU & 6 years FU & 8 years FU & 10 years FU & 12 years FU & 14 years FU \\
\hline BIV QRS $<164 \mathrm{~ms}$ & 42 & 41 & 39 & 35 & 29 & 25 & 25 & 25 \\
\hline BIV QRS $>164 \mathrm{~ms}$ & 46 & 41 & 38 & 31 & 25 & 18 & 16 & 14 \\
\hline
\end{tabular}

(C)

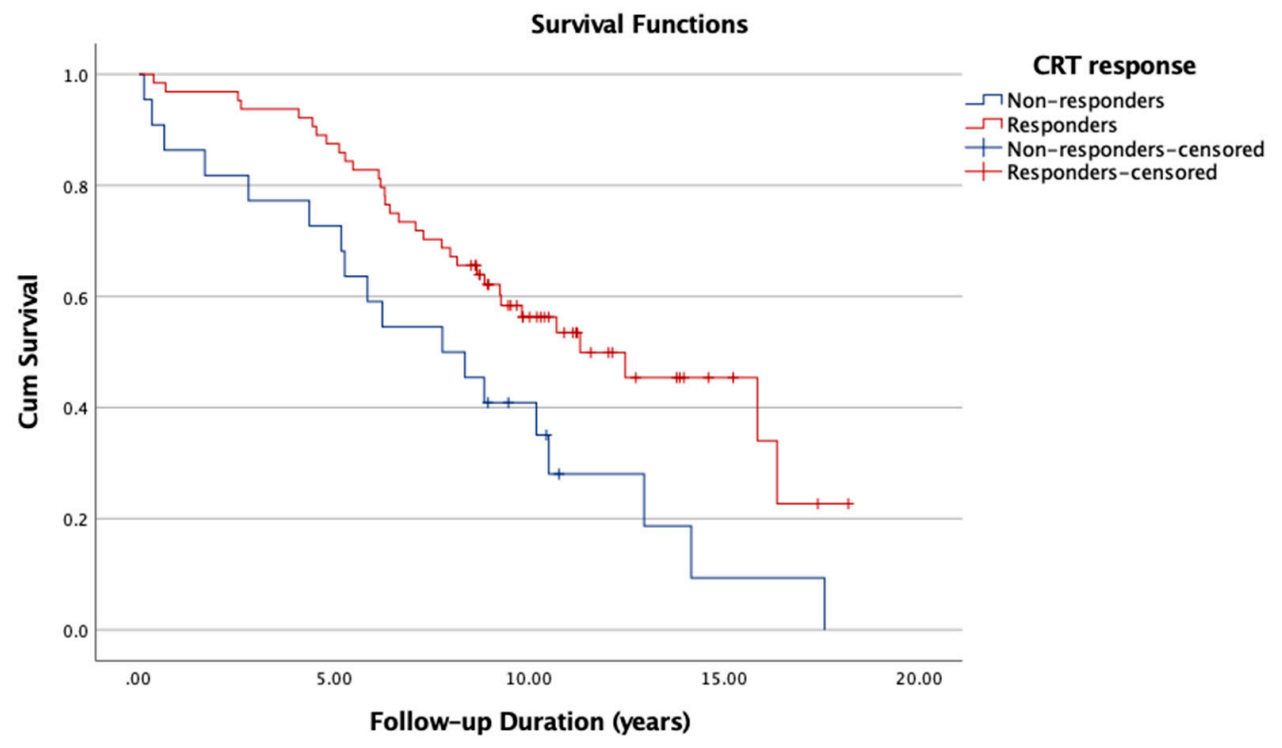

\begin{tabular}{ccccccccc}
\hline No. at risk & 0 years FU & 2 years FU & 4 years FU & 6 years FU & 8 years FU & 10 years FU & 12 years FU & 14 years FU \\
\hline Non-responders & 21 & 18 & 17 & 13 & 11 & 9 & 7 & 6 \\
\hline Responders & 67 & 62 & 60 & 53 & 43 & 36 & 34 & 33 \\
\hline
\end{tabular}

Figure 2. Kaplan-Meier survival functions, with corresponding tables describing the number (N) of patients at risk at a given point of the follow-up, for presence of NICM vs. ICM (Panel A); patients with NYHA III vs. NYHA IV at the time of implantation (Panel B). Patients with upper vs. lower median of QRS width during biventricular pacing (Panel C), as well as clinical responders to CRT therapy vs. non-responders to CRT therapy (Panel D). (NICM: non-ischemic cardiomyopathy; NYHA: New York Heart Association; BIV: biventricular pacing; ICM: ischemic cardiomyopathy; Cum survival: cumulative survival; ms: milliseconds; CRT: cardiac resynchronization therapy). 


\section{Discussion}

In the present study, a shorter QRS width during biventricular pacing in the first months after CRT implantation, as well as lower NYHA class and the presence of nonischemic (compared to ischemic) cardiomyopathy, independently predicted cardiovascular survival in patients with class I indication for cardiac resynchronization therapy over a very long-term follow-up. Other ECG parameters that were shown to predict short-term clinical response to CRT (i.e., QRS width of LV or RV pacing, native QRS width, difference between LV and RV paced QRS) did not predict long-term survival. Of note, shorter QRS width during biventricular pacing did not predict a short-term clinical response in our original paper.

Several studies were able to demonstrate the beneficial effect of QRS narrowing on CRT response rate, survival, and ventricular remodeling [8,9]. A recent meta-analysis of 32 studies from Bazoukis et al. sought to review the association between QRS narrowing through CRT and clinical, as well as echocardiographic, response [10]. The quantitative synthesis showed that patients with clinical improvement exhibited shorter QRS durations through CRT. The same was seen with echocardiographic response, although, in contrast to clinical response, not all of the retained studies showed favorable results.

Our cohort adds further positive data on the effect of QRS narrowing through CRT on very long-term survival. In daily clinical practice, this simple ECG parameter might be of particular value, due to being readily available, in contrast to more sophisticated and costly diagnostics [11], with little interobserver variability. Our data may thus be of clinical relevance as they are easily integrable in the implantation routine in cases where more than one target vein can be selected.

The quest for optimal QRS narrowing should not stop with lead placement. Recent data of Verma et al. showed the importance of a patient-tailored individual device programming to obtain optimal QRS narrowing [12]. In a well-selected collective, with optimal LV lead placement, using a device-based algorithm, which automatically adjusted the paced atrioventricular delay, the authors obtained QRS narrowing during BIV pacing, regardless of underlying cardiomyopathy or the native QRS width. Further, as proposed by Jastrzebski et al., in patients where QRS narrowing through CRT cannot be achieved, despite optimal programming, HIS bundle or left bundle branch pacing seems to be an attractive option [13]. Although long-term data on hard endpoints are lacking, QRS narrowing might not be beneficial for all patients. Previous data showed only patients with LBBB seemed to benefit from device-induced QRS narrowing [13].

Our multivariate analysis also revealed the presence of NICM to be an independent predictor of survival over our very long follow-up. Moreover, we were able to show the independent predictive value of the patients' NYHA class for long-term survival. In short, up to median duration follow-up, several previous studies also reported patients' NYHA classes and their underlying cardiomyopathy to be independent predictors of survival in CRT [14-17]. The superior response to CRT in NICM and in patients with a lower burden of symptoms has been known since the first randomized CRT trials, like MADIT-CRT, albeit over a shorter follow-up period. The landmark MADIT-CRT trial showed cardiac resynchronization therapy with defibrillator (CRT-D) to reduce rates of mortality or heart failure events when compared to implantable cardioverter defibrillator (ICD) placement alone among heart failure patients with LVEF $\leq 30 \%$ and QRS duration $\geq 130 \mathrm{msec}$ [18]. This benefit is primarily driven by a reduction in HF events. The cohort of 1820 patients comprised patients with a lower NYHA class (NYHA I-II exclusively) and a greater percentage of ICM, in comparison to our population. A secondary analysis of MADIT-CRT found patients with NICM and lower NYHA class to show a greater response to CRT [19]. The 7-year follow-up results from the trial revealed a cumulative rate of all-cause mortality for the CRT patients of 18\% [20]. At the 7-year follow-up, we saw a cumulative rate of all-cause mortality of $31 \%$, which can be attributed to the advanced age and higher NYHA class of our cohort. Nearly half of our elderly patient population were still alive at the end of our median follow-up of 10.3 years. As novel drug 
developments (e.g., the landmark DAPA-HF and PARADIGM-HF trials) boost survival through new pharmacological therapies, long-term survival rates will likely increase in the future $[21,22]$.

Of note, although response to CRT and NT-proBNP showed in the univariate analysis a strong correlation with outcome, it did not retain its statistical significance in our multivariate model. We opted to define response to CRT using clinical improvement in NYHA class; however, in the published literature there is a lack of consensus on the definition of response to CRT [23]. The predictive value of the different criteria used to define response to CRT varies considerably. Boidol et al. were able to show clinical characteristics to exhibit a higher sensitivity, whereas echocardiographic measurements showed a higher specificity in the context of predicting survival [24]. Their data from the TRUST CRT trial found improvement in NYHA class to be a powerful predictor of outcome. However, due to multiple interactions with baseline characteristics, the accuracy varied significantly throughout different subgroups.

Finally, device-related complications remain a major cause of morbidity in CRT patients. In our cohort, we saw comparably low complication rate of $2.9 \%$ over the complete follow-up (three patients with device-related endocarditis). Previous data from the Italian Clinical Service project reported rates of device-related infections of 0.9 events per 100 patient-years after the first implantation, and 1.8 events per 100 patient-years after the device replacement procedure [25]. None of our subjects presented recurring infections after device replacement.

\section{Limitations}

A major limitation to our study is due to its design. We present a prospective observational study without randomization with a relatively small sample size. Due to the non-continuous follow-up, we do not have sufficient data on the time varying and the disease or on the survival modifying factors and we cannot account for an eventual interference with our potential predictors for survival. However, we prospectively evaluated a real-world CRT population over a very long period of time.

\section{Conclusions}

During very long-term follow-up, we were able to add further evidence relative to the importance of QRS shortening through CRT. The easily obtainable ECG parameters should be one of the main endpoints of resynchronization. LV lead placement, as well as device programming, should be adjusted to obtain maximal QRS shortening. Our data strengthen the status of the underlying cardiomyopathy, as well as the NYHA class, in patient selection for resynchronization therapy.

Author Contributions: Conceptualization, D.G.D., J.K., L.E. and P.L.; methodology, P.L., D.G.D. \& J.K.; software, F.G. \& C.E.; validation, P.L., L.E., F.R., B.R. and D.G.D.; formal analysis, P.L. \& D.G.D.; investigation, C.A. \& B.R.; resources, L.E. \& G.F.; data curation, C.A. \& J.W.; writing—original draft preparation, P.L., D.G.D., L.E. \& J.K.; writing—review and editing, all authors; visualization, J.K..; supervision, L.E. \& D.G.D.; project administration, P.S.L.; funding acquisition, L.E. All authors have read and agreed to the published version of the manuscript.

Funding: We acknowledge support from the Open Access Publication Fund of the University of Muenster.

Institutional Review Board Statement: The study was conducted in accordance with the University of Münster Ethical Committee and Institutional Review Board. It has been performed in accordance with the ethical standards laid down in the 1964 Declaration of Helsinki and its later amendments.

Informed Consent Statement: Patient consent was waived due to retrospective data collection.

Data Availability Statement: The datasets used and/or analysed during the current study are available from the corresponding author on reasonable request.

Acknowledgments: The authors would like to thank Pol Leitz for his support in finalizing the project.

Conflicts of Interest: The authors declare that they have no competing interest. 


\section{References}

1. Roger, V.L. Epidemiology of heart failure. Circ. Res. 2013, 113, 646-659. [CrossRef]

2. Bristow, M.R.; Krueger, S.; Carson, P.; White, B.G. Cardiac-Resynchronization Therapy with or without an Implantable Defibrillator in Advanced Chronic Heart Failure. N. Engl. J. Med. 2004, 350, 2140-2150. [CrossRef]

3. Cleland, J.G.F.; Erdmann, E.; Kappenberger, L. The Effect of Cardiac Resynchronization on Morbidity and Mortality in Heart Failure. N. Engl. J. Med. 2005, 352, 1539-1549. [CrossRef]

4. Köbe, J.; Dechering, D.G.; Rath, B.; Reinke, F.; Mönnig, G.; Wasmer, K.; Eckardt, L. Prospective evaluation of electrocardiographic parameters in cardiac resynchronization therapy: Detecting nonresponders by left ventricular pacing. Heart Rhythm 2012, 9 , 499-504. [CrossRef]

5. Appert, L.; Menet, A.; Altes, A.; Ennezat, P.V.; Bardet-Bouchery, H.; Binda, C.; Guyomar, Y.; Delelis, F.; Castel, A.-L.; Goffic, C.L.; et al. Clinical Significance of Electromechanical Dyssynchrony and QRS Narrowing in Patients With Heart Failure Receiving Cardiac Resynchronization Therapy. Can. J. Cardiol. 2019, 35, 27-34. [CrossRef]

6. Dickstein, K.; Vardas, P.E.; Auricchio, A.; Daubert, J.C.; Linde, C.; McMurray, J.; Ponikowski, P.; Priori, S.G.; Sutton, R.; van Veldhuisen, D.J.; et al. 2010 Focused Update of ESC Guidelines on device therapy in heart failure: An update of the 2008 ESC Guidelines for the diagnosis and treatment of acute and chronic heart failure and the 2007 ESC guidelines for cardiac and resynchronization therapy Developed with the special contribution of the Heart Failure Association and the European Heart Rhythm Association. Eur. Heart J. 2010, 12, 1526-1536.

7. Kutyifa, V.; Breithardt, O.A. How to Assess the Nonresponder to Cardiac Resynchronization Therapy-A Comprehensive Stepwise Approach. Rev. Esp. Cardiol. Engl. Ed. 2012, 65, 504-510. [CrossRef] [PubMed]

8. Rickard, J.; Popovic, Z.; Verhaert, D.; Sraow, D.; Baranowski, B.; Martin, D.O.; Lindsay, B.D.; Varma, N.; Tchou, P.; Grimm, R.A.; et al. The QRS Narrowing Index Predicts Reverse Left Ventricular Remodeling Following Cardiac Resynchronization Therapy. Pacing Clin. Electrophysiol. 2011, 34, 604-611. [CrossRef]

9. Bryant, A.R.; Wilton, S.B.; Lai, M.P.; Exner, D.V. Association between QRS duration and outcome with cardiac resynchronization therapy: A systematic review and meta-analysis. J. Electrocardiol. 2013, 46, 147-155. [CrossRef] [PubMed]

10. Bazoukis, G.; Naka, K.K.; Alsheikh-Ali, A.; Tse, G.; Letsas, K.P.; Korantzopoulos, P.; Liu, T.; Yeung, C.; Efremidis, M.; Tsioufis, K.; et al. Association of QRS narrowing with response to cardiac resynchronization therapy-A systematic review and meta-analysis of observational studies. Heart Fail. Rev. 2020, 25, 745-756. [CrossRef]

11. Ter Horst, I.A.; Bogaard, M.D.; Tuinenburg, A.E.; Mast, T.P.; de Boer, T.P.; Doevendans, P.A.; Meine, M. The concept of triple wavefront fusion during biventricular pacing: Using the EGM to produce the best acute hemodynamic improvement in CRT. Pacing Clin. Electrophysiol. 2017, 40, 873-882. [CrossRef] [PubMed]

12. Varma, N.; O’Donnell, D.; Bassiouny, M.; Ritter, P.; Pappone, C.; Mangual, J.; Cantillon, D.; Mangual, J.; Cantillon, D.; Badie, N. Programming Cardiac Resynchronization Therapy for Electrical Synchrony: Reaching Beyond Left Bundle Branch Block and Left Ventricular Activation Delay. J. Am. Heart Assoc. 2018, 7, e007489. [CrossRef] [PubMed]

13. Jastrzębski, M.; Baranchuk, A.; Fijorek, K.; Kisiel, R.; Kukla, P.; Sondej, T.; Czarnecka, D. Cardiac resynchronization therapyinduced acute shortening of QRS duration predicts long-term mortality only in patients with left bundle branch block. EP Eur. 2019, 21, 281-289. [CrossRef]

14. Schuchert, A.; Muto, C.; Maounis, T.; Frank, R.; Ella, R.O.; Polauck, A.; Padeletti, L. One-year outcome after CRT implantation in NYHA class IV in comparison to NYHA class III patients. Clin. Res. Cardiol. 2013, 102, 505-511. [CrossRef] [PubMed]

15. McLeod, C.J.; Shen, W.K.; Rea, R.F.; Friedman, P.A.; Hayes, D.L.; Wokhlu, A.; Webster, T.L.; Wiste, H.J.; Hodge, D.O.; Bradley, D.J.; et al. Differential outcome of cardiac resynchronization therapy in ischemic cardiomyopathy and idiopathic dilated cardiomyopathy. Heart Rhythm 2011, 8, 377-382. [CrossRef]

16. Mangiavacchi, M.; Gasparini, M.; Faletra, F.; Klersy, C.; Morenghi, E.; Galimberti, P.; Genovese, L.; Regoli, F.; De Chiara, F.; Bragato, R.; et al. Clinical predictors of marked improvement in left ventricular performance after cardiac resynchronization therapy in patients with chronic heart failure. Am. Heart J. 2006, 151, 477.e1-477.e6. [CrossRef] [PubMed]

17. Cleland, J.G.; Abraham, W.T.; Linde, C.; Gold, M.R.; Young, J.B.; Claude Daubert, J.; Sherfesee, L.; Wells, G.A.; Tang, A.S.L. An individual patient meta-analysis of five randomized trials assessing the effects of cardiac resynchronization therapy on morbidity and mortality in patients with symptomatic heart failure. Eur. Heart J. 2013, 34, 3547-3556. [CrossRef]

18. Moss, A.J.; Hall, W.J.; Cannom, D.S.; Klein, H.; Brown, M.W.; Daubert, J.P.; Mark Estes, N.A., III; Foster, E.; Greenberg, H.; Higgins, S.L.; et al. Cardiac-Resynchronization Therapy for the Prevention of Heart-Failure Events. N. Engl. J. Med. 2009, 361, 1329-1338. [CrossRef]

19. Barsheshet, A.; Goldenberg, I.; Moss, A.J.; Eldar, M.; Huang, D.T.; McNitt, S.; Klein, H.U.; Hall, W.J.; Brown, M.W.; Goldberger, J.J.; et al. Response to preventive cardiac resynchronization therapy in patients with ischaemic and nonischaemic cardiomyopathy in MADIT-CRT. Eur. Heart J. 2011, 32, 1622-1630. [CrossRef]

20. Goldenberg, I.; Kutyifa, V.; Klein, H.U.; Cannom, D.S.; Brown, M.W.; Dan, A.; Daubert, J.P.; Mark Estes, N.A.; Foster, E.; Greenberg, H.; et al. Survival with Cardiac-Resynchronization Therapy in Mild Heart Failure. N. Engl. J. Med. 2014, 370, 1694-1701. [CrossRef]

21. McMurray, J.J.; Solomon, S.D.; Inzucchi, S.E.; Køber, L.; Kosiborod, M.N.; Martinez, F.A.; Ponikowski, P.; Sabatine, M.S.; Anand, I.S.; Bělohlávek, J.; et al. Dapagliflozin in Patients with Heart Failure and Reduced Ejection Fraction. N. Engl. J. Med. 2019, 381, 1995-2008. [CrossRef] 
22. McMurray, J.J.; Packer, M.; Desai, A.S.; Gong, J.; Lefkowitz, M.P.; Rizkala, A.R.; Rouleau, J.L.; Shi, V.C.; Solomon, S.D.; Swedberg, K.; et al. Angiotensin-Neprilysin Inhibition versus Enalapril in Heart Failure. N. Engl. J. Med. 2014, 371, 993-1004. [CrossRef] [PubMed]

23. Fornwalt, B.K.; Sprague, W.W.; BeDell, P.; Suever, J.D.; Gerritse, B.; Merlino, J.D.; Fyfe, D.A.; León, A.R.; Oshinski, J.N. Agreement Is Poor Among Current Criteria Used to Define Response to Cardiac Resynchronization Therapy. Circulation 2010, 121, $1985-1991$. [CrossRef] [PubMed]

24. Boidol, J.; Średniawa, B.; Kowalski, O.; Szulik, M.; Mazurek, M.; Sokal, A.; Pruszkowska-Skrzep, P.; Kukulski, T.; Kalarus, Z.; Lenarczyk, R. Triple-Site Versus Standard Cardiac Resynchronisation Trial (TRUST CRT) Investigators. Many response criteria are poor predictors of outcomes after cardiac resynchronization therapy: Validation using data from the randomized trial. Europace 2013, 15, 835-844. [CrossRef] [PubMed]

25. Landolina, M.; Gasparini, M.; Lunati, M.; Iacopino, S.; Boriani, G.; Bonanno, C.; Vado, A.; Roclemer, A.; Capucci, A.; Zucchiatti, C.; et al. Long-Term Complications Related to Biventricular Defibrillator Implantation. Circulation 2011, 123, $2526-2535$. [CrossRef] [PubMed] 